\title{
Education and Training of Small-Scale Entrepreneurs: A Tool for Poverty Reduction in the Nkoranza South Municipality, Ghana
}

\author{
Richard Baah-Mintah $^{1, *}$, Ellen Owusu-Adjei ${ }^{1}$, Frederick Koomson ${ }^{2}$ \\ ${ }^{1}$ Department of Development and Management Studies, Anglican University College of Technology \\ ${ }^{2}$ Institute for Development Studies, University of Cape Coast \\ *Corresponding author: rb.mintah@ angutech.edu.gh
}

Received July 09, 2018; Revised August 11, 2018; Accepted September 17, 2018

\begin{abstract}
Educating and training of small-scale entrepreneurs has been identified as key determinants in the establishment, growth, and survival of businesses which ultimately reduce poverty levels. In spite of the relationship that exists between education and training and poverty reduction among small-scale entrepreneurs, very little empirical examination has been done. This informed the current study to examine how educating and training of small-scale entrepreneurs by the Business Advisory Centre (BAC), a promotional institution, contribute to poverty reduction in the Nkoranza South Municipality (NSM). The study employed descriptive and evaluative designs. All the small-scale entrepreneurs who were registered with the BAC were included in the study. The systematic and purposive sampling methods were used to draw 278 small-scale entrepreneurs and three members of staff of the BAC. Questionnaires, interviews guide and focus group discussion guide were principally used to collect data from the respondents. The results from the study showed that the Business Advisory Centre (BAC), with its education and training programmes in the municipality has, to a large extent helped reduce the poverty levels among entrepreneurs. This was observed in increased outputs, incomes and levels of savings among the respondents. The study recommends to the $\mathrm{BAC}$ to increase the coverage and intensifies its education and training within the municipality.
\end{abstract}

Keywords: education, training, poverty, small-scale, entrepreneurs

Cite This Article: Richard Baah-Mintah, Ellen Owusu-Adjei, and Frederick Koomson, "Education and Training of Small-Scale Entrepreneurs: A Tool for Poverty Reduction in the Nkoranza South Municipality, Ghana." Journal of Business and Management Sciences, vol. 6, no. 4 (2018): 143-151. doi: 10.12691/jbms-6-4-2.

\section{Introduction}

Over the years, the need for countries, especially developing countries, to embark on programmes of industrialisation has been put forward by many scholars and policy makers. Internationally, robust industrial sector plays a critical role in achieving decent socio-economic development and for that matter prosperity for the citizens of any nation [1]. Industrialisation is, consequently, seen as the way forward especially for countries in Africa, Asia and the Latin America where over 760 million of the world's poor people reside [2,3]. This is mainly because industries provide the impetus for increase in productivity and income generation which eventually have a trickle-down effect on all sectors of a country's economy i.e. growth in gross domestic product (GDP), favourable balance of payments, income distribution, rural development, and poverty reduction.

In discussing industrialisation, contributions of smallscale industries (SSIs) are often neglected with attention given to the large-scale industries. However, the smallscale enterprises are important for developing countries as they are powerful engine of economic growth, job creation and poverty reduction [4]. For instance, the SSIs accounts for about 95 percent of employment and about 43 percent of the value added of the entire industrial sector $[5,6]$. With their operations, economic development is spread across the length and breadth of a given region, reducing inequality and extreme poverty among the entrepreneurs and their workers.

In spite of the contribution of this sector towards the development of countries, there are several challenges that the industry is saddled with. Key among such challenges is the fact that most of the small-scale entrepreneurs do not have sufficient education and training that will place them in a better position to excel in their businesses [7]. This situation often translates into poor business and management practices which do not help in the development of small- scale businesses. Educating and training small-scale entrepreneurs has been argued as a key necessity to the development and growth of smallscale enterprises in many countries. This is mainly because through education and training, entrepreneurs develop skills, attitudes and knowledge which all together offers them the opportunity to establish and also expand their enterprises. 
The literature is replete with several studies showing how important education and training are to entrepreneurs in general and small-scale entrepreneurs in particular. For instance, researchers such as Abrisham and Khadijeh [8] and Burchi and De Muro [9] have indicated that providing education and training for rural entrepreneurs contribute positively to their productivity, ensures food security, enhance their livelihoods and ultimately reduce their levels of poverty. Any effort aimed at poverty reduction and breaking the poverty cycle, especially in developing countries where small-scale enterprises are in preponderance, should recognise education and training of small-scale entrepreneurs as a strategy for addressing poverty. This will go a long way in helping countries achieve the Sustainable Development Goals (especially Goal 1) which aims at ending poverty in all its forms everywhere.

The importance of education and training is at the heart of the human capital theory. Education and training of the human resource, according to the human capital theorists, is more important than the provision of social services such as housing, drinking water, electricity and transport. Educating and training a person enables him or her to acquire skills and become competitive and also contribute to economic development. The human capital of a country consequently is perceived globally as a determinant of economic development $[10,11]$. The Human capital theory opines that education and training create skills which facilitate higher levels of productivity and income amongst those who possess them in comparison to those who do not $[12,13,14]$.

The definition for small-scale industry differs among countries and organisations. For instance, while some look at the level of employment, others stress on the level of investment, turnover, legal status or method of production. In Ghana, the Ghana Statistical Service (GSS) broadly defines small-scale industry in terms of the number of people employed. The Ghana Statistical Service [15] by implication defines small-scale industry as an establishment or entity with less than 10 employees where those with employees of 10 and above are considered medium and large- scale. Relevant characteristics of a small-scale industry are evident in areas which include: source of capital; location and regulation, education and training of entrepreneurs, gender, knowledge of supporting agencies [16].

The debate in favour of promoting the small-scale industry in Ghana continues to be at the forefront in any attempt at development. This is partly because businesses in Ghana are dominated by small-scale enterprises which are mostly at the informal level [17]. The industry contributes greatly to the economic development and poverty reduction in Ghana and other developing countries. It is estimated that the small- scale together with the medium-scale industries contribute about 70 percent of Ghana's gross domestic product (GDP), forms about 92 percent of her businesses and employs about 22 percent of the adult population in Ghana [18]. Most of these smallscale enterprises are located in the rural areas, promoting these enterprises, therefore, means diversifying the rural economy and spurring capital formation (savings) resulting from increased productivity and income of entrepreneurs.

One major means to promote these small scale-scale enterprises is through education and training. Educating and training small-scale entrepreneurs will increase their productivity, profitability and ultimately reduce the poverty levels among such entrepreneurs. It is for this reason, inter alia, that promotional institutions such as the Business Advisory Centre (BAC) of the National Board for Small Scale Industries (NBSSI), Ghana Appropriate Technology Services (GRATIS), and Microfinance and Small Loan Centre (MASLOC) were established in Ghana by successive governments mainly to provide educational and training services, which most entrepreneurs especially small-scale entrepreneurs lack [19,20]. Promotional institutions for small-scale industries in the Nkoranza South municipality primarily include the BAC of the NBSSI, banking institutions and the Municipal Assembly. Out of these promotional institutions, it is the BAC which is responsible for providing relevant information, education and training, and providing guidance (non-financial services) to entrepreneurs.

The justification of the study lies in the fact that, despite the existence of these promotional institutions in the Nkoranza South Municipality, there is little or no specific empirical evidence on how such education and training programmes provided by such institutions have helped in reducing poverty among the educated and trained small-scale entrepreneurs. As the main objective, this study, sought to systematically examine how the education and training services provided by the BAC has contributed to poverty reduction among small-scale entrepreneurs in the Nkoranza South Municipality.

\section{Literature Review}

\section{Education and training of small-scale entrepreneurs and poverty reduction}

Education and training have been used as avenues to increase productivity levels of small-scale entrepreneurs and further spur economic growth among countries [21]. Education and training are vital ingredients in building entrepreneurship and fostering innovation [22]. Such education and training are aimed at reinforcing knowledge, skills and attitude of entrepreneur. In a joint study by the Food and Agricultural Organization (FAO) and UNESCO in 2003 [23], it was concluded that, education and training are two of the most powerful weapons in an effort to reduce poverty in particular and achieving development in general. The importance of education and training is reiterated by the human capital theory which sees education and training as investment and a generator of externalities.

The human capital theory looks at the basic set of marketable skills of an individual (worker) as a form of capital. It lays much emphasis on the stock of knowledge or characteristics that an individual has which contributes to his or her productivity. This stock of knowledge may be either innate or acquired. In the production process as indicated by [24], the human capital is directly useful. He posits that investment in education and health care are key in improving upon the human capital which ultimately increase a worker's productivity. The human capital is the foundation of economic productivity [11]. Schultz emphasises five areas that need investment. These areas are: education, on-the-job training, study programmes for 
adults, health and migration of individuals and families. The human capital theory perceives education and training, which is an investment in knowledge, skills and attitude, to have a strong economic impact on productivity $[12,14]$.

Advocates opine that the growth and survival of enterprises are to a large extent contingent on education and training [25]. In looking at the role of education and training in poverty reduction among small-scale entrepreneurs, the debate which often arises is which type of education should be given to entrepreneurs. This question is relevant as many studies have stressed on formal education to the neglect of the other forms of education. The argument, however, is that education is not limited to instructions that are given and received in schools alone (formal education). All the other forms of education be it non-formal which is education that takes place within and outside educational institutions and cater for all ages and informal education which occurs through everyday interaction with the environment that offer information and insight should be looked at.

The education and training programmes designed for small-scale entrepreneurs need to be tailored to suit their needs. Such programme should aim at improving productivity of entrepreneurs, their income levels and standards of living (reduce poverty). The education and training programmes should be in areas such as technical and vocational skills, business and management (book keeping, profit calculation, managing inventory), financial education (managing profit, making inter-temporal decisions on investment and savings and accounting), life skills, financial support (loans and grants), counselling and other advisory services, mentoring, micro-franchising, enabling value chain inclusion, small business networks, support for technology transfer, business incubation and many others According to [26,27].

Over the years, there has been a growing concern about the role of entrepreneurial education and training as a catalyst to achieve a number of economic and social development $[28,29]$. Education and training is eminent in all the stages of the business cycle. It is important at the business start-up, crises and/or survival [30]. In recognition of the importance of education and training together with other ancillary services that small-scale entrepreneurs in Ghana may need, several bodies have been over the years been established. Notable among such bodies include the National Board for Small-Scale Industries (NBSSI) with its Business Advisory Centre (BAC); Ghana Regional Appropriate Technology and Industrial Service (GRATIS); Development and Application of Intermediate Technology Project (DAPIT); Technology Consultancy Centre (TCC); National Vocational and Technical Institute (NVTI) and Rural Enterprise Programme (REP) [31,32]. These institutions were set up to be a catalyst in providing and creating conditions suitable and favourable for the development of the smallscale enterprises in Ghana.

The effects of education and training programmes provided by such institutions are seen in stimulating the growth of economies around the globe. This is often the case because of the backward and forward linkages small-scale industries have with other sectors in an economy. A study by [33] revealed how educating and training small-scale entrepreneurs affect their productivity, income and reduce their poverty levels. With an increase income, Polak argues that the poor are able to buy food to assuage their hunger, their families become healthier, afford improved shelter, educate their children and acquire property. Again, some studies [28,34,35] have explicitly concluded that there is a positive correlation between education and training of entrepreneurs and the successes of their businesses as they were able to produce more for the market, ensures effective and efficient utilisation of limited resources and also are able to adopt appropriate and new technologies in their production.

With all these importance of education and training the growth and survival of all businesses, one generalization which is valid is that education and training are less likely available to small-scale enterprises than to those in large companies [20]. Despite the establishment of these promotional institutions, there is still knowledge and skills gap when it comes to education and training among small-scale entrepreneurs. It is largely argued that most small-scale entrepreneurs lack entrepreneurial and business management skills in areas such as basic accounting, bookkeeping, income management, feasibility studies and business plan preparation required by most financial institutions [19,36,37]. As a result, small-scale entrepreneur are unable to reap the benefits thereof with their businesses. The effect of this is what is seen in Figure 1.

As can be seen from Figure 1, low level of education and training of small-scale entrepreneurs (SSEs) means low level of human capital in the small-scale industry. This reflects in low productivity, low income and savings which further heightens the incidence of poverty among small-scale entrepreneurs. Judging from potentials that education and training present, the onus lies on governments, promotional institutions, non-governmental organisations and other agencies to ensure that small-scale entrepreneurs are given the required education and training to enable them excel in their businesses.

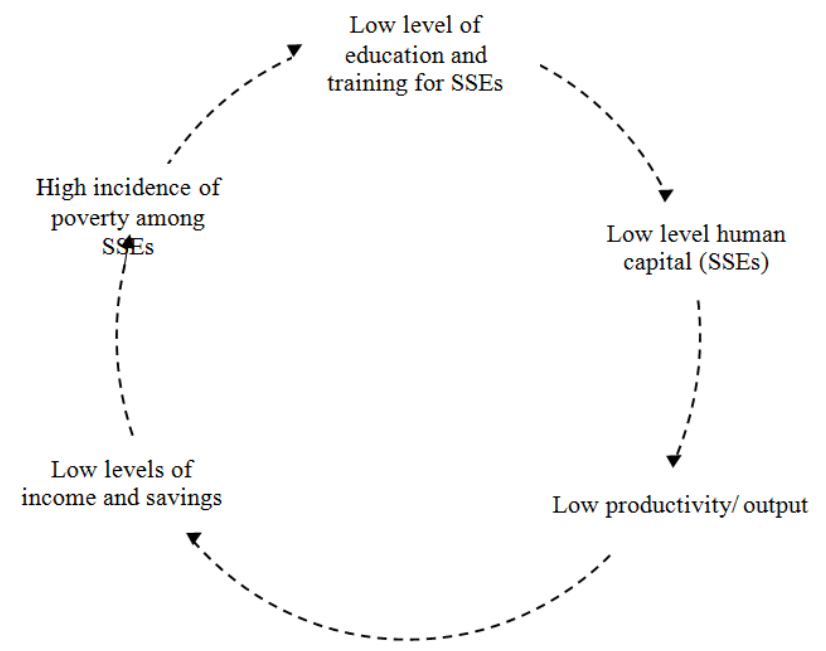

Figure 1. The poverty trap among small-scale entrepreneurs (Source: Adapted from [38] 'Little Opportunity Circle')

The key to breaking this circle as seen in Figure 2 lies in providing education and training programmes for smallscale entrepreneurs. Providing education and training services to small-scale entrepreneurs has the potential of empowering them, by increasing their self-confidence, 
their capacity to improve their livelihoods and their participation in wider processes of social and economic change [23]. Often times, some researchers place much emphasis on lack of capital as the major constraint facing SSIs [39]. However, one key argument in favour of education and training is that a clear obstacle to enterprise growth is not only lack of capital, but also lack of entrepreneurial and occupational skills which is often neglected. Besides, if capital is made available to entrepreneurs, without the right kind of knowledge and information they are bound to fail in their businesses [40,41].

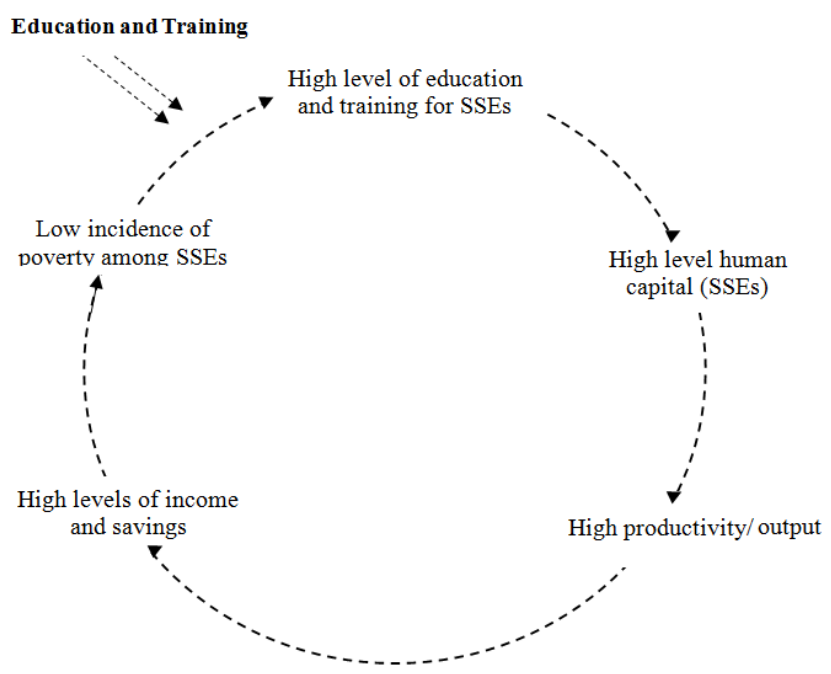

Figure 2. Conceptual framework for breaking the poverty trap among small-scale entrepreneurs through education and training (Source: Authors' construct, 2017)

As argued by Schultz [11] human skills and accumulation of useful knowledge forms the foundation of economic productivity. Education and training create skills which facilitate higher levels of productivity among those who possess them in comparison to those who do not. Entrepreneurs are in a position to introduce changes and innovation in their businesses. They are able to engage in better management practices, expand their businesses and create more job opportunities for the teeming population. Others are in a better position to establish new businesses $[42,43]$.

Even though costly, the benefits derived from education and training as can be seen in Figure 2 are of great magnitude. It results in higher level human capital (among small-scale entrepreneurs), high productivity/output, high income levels and savings and ultimately reduction in the incidence of poverty $[33,44]$. This will result in entrepreneurs' ability to provide medical care, good education, nutritious food, shelter, clothing, and their ability to acquire property and asset [33]. In the Nkoranza South Municipality, the provision of education and training services lie with the Business Advisory Centre (BAC).

\section{Methodology}

The study employed the descriptive and evaluative designs to assess how entrepreneurial education and training has contributed to poverty reduction among small-scale entrepreneurs in the Nkoranza South Municipality. The descriptive design made it possible to obtain information on the current status of the small-scale entrepreneurs and their businesses and also the operations of the BAC in the study area. The evaluative design on the other hand helped in assessing the extent to which the education and training programmes by the BAC has helped in reducing poverty among entrepreneurs.

Assuming a 5 percent margin of error and 95 percent confidence using a table by [45], a sample size of 278 small-scale entrepreneurs was drawn from the 1,012 entrepreneurs registered with the Business Advisory Centre under the National Board for Small-Scale Industries (NBSSI) and have been in existence for three years and above in the municipality. The enterprises from which these respondents were drawn were grouped under four thematic areas, namely: traditional craft businesses, agro-processing, agro-industry and farm-based businesses with membership strength of 149, 197, 244 and 422 respectively. The respondents were proportionately drawn from these four groupings. The systematic sampling method, which is a probability method, was used to draw 41, 54, 67 and 116 respondents from the traditional craft, agro-processing, agro-industry and farm-based businesses respectively.

Three officials of the promotional institution, the BAC of the National Board for Small-Scale Industries (NBSSI) were purposively selected for the study. Their selection was based on the assumption they are knowledge about the operations of the BAC in the municipality. Both primary and secondary data were collected. Primary data were collected from respondents through field survey. The secondary sources of data included official documents from BAC, internet, relevant theses, books, reports, publications and journals. Questionnaire was used to collect data from the sampled small-scale entrepreneurs. Entrepreneurs who could read and write were given the questionnaires to complete. However, in the case of those who could not read and write, the questionnaires were administered as interview schedules. In the case of the key informants, interview schedule and focused group discussion (FGD) were used to collect data. A five-point Likert scale items format was used in collecting data to assess the effect of education and training of entrepreneurs on poverty reduction among small-scale entrepreneurs.

Data collected were edited, coded and organised in a form that allowed for easy entry and analysis by the computer. The Statistical Product and Service Solutions (SPSS Version 21) software and Microsoft Excel (2016) were used for data processing and analysis. The data were grouped and described using tables, graphs, charts as well as descriptive statistics. The Wilcoxon Signed-Ranked test, a non-parametric test, was used to determine the effect of education and training on the output, income and savings levels of entrepreneurs. The results are presented in the next section.

\section{Results and Discussion}

This section of the paper is devoted to the analysis of the data and the discussion of the results on how entrepreneurial education and training can be used as 
a tool in reducing poverty in the Nkoranza South Municipality. The section includes the profile of respondents; BAC's operations in the Nkoranza South Municipality; the effect of education and training on businesses and poverty reduction among entrepreneurs; challenges facing educated and trained small-scale entrepreneurs; and challenges facing BAC in their operations in the Nkoranza South Municipality.

\subsection{Profile of Respondents}

The background characteristics of the respondents as presented in Table 1 includes the sex, educational levels and years of operation of the respondents. From the table, it is discernible that the majority $(76.6 \%)$ of the sampled respondents (entrepreneurs) were female, the rest were males. This corroborates the findings of [46] that women are in the majority in small-scale industry in Ghana.

In the stance of the entrepreneurs, a greater proportion (44.3\%) had Basic level education while 17.3 percent had Senior High School, Vocational or Technical education. However, $1.4 \%$ of the entrepreneurs had a university degree with 32.7 percent not having any formal education. It is evident from the study that a sizeable proportion of the entrepreneurs had no formal education. This supports the findings of [47] and [48] that most small-scale entrepreneurs in Ghana have not acquired formal education.

Table 1. Profile of respondents

\begin{tabular}{|c|c|c|}
\hline \multirow[t]{2}{*}{ Response } & \multicolumn{2}{|c|}{ Small-scale Entrepreneurs } \\
\hline & Freq. & Percent \\
\hline \multicolumn{3}{|l|}{$\operatorname{Sex}$} \\
\hline Male & 65 & 23.4 \\
\hline Female & 213 & 76.6 \\
\hline Total & 278 & 100 \\
\hline \multicolumn{3}{|l|}{ Education } \\
\hline No formal education & 91 & 32.7 \\
\hline Basic education & 123 & 44.3 \\
\hline SHS/Voc./Tech & 48 & 17.3 \\
\hline College/Poly & 12 & 4.3 \\
\hline University & 4 & 1.4 \\
\hline Total & 278 & 100 \\
\hline \multicolumn{3}{|l|}{ Years of operation } \\
\hline $3-5$ years & 132 & 47.5 \\
\hline $6-10$ years & 89 & 32.0 \\
\hline $10+$ & 57 & 20.5 \\
\hline Total & 278 & 100 \\
\hline
\end{tabular}

Source: Fieldwork, 2017.

It is mostly argued that, older businesses/entrepreneurs have more experience than younger ones. The study, therefore, ascertained the years of operation of the entrepreneurs. As shown in Table 1, 47.5 percent of the entrepreneurs had been in operation for a period between 3-5 years with 23 percent being in operation for a period of between 6-10 years. Again, 20.5\% of the entrepreneurs indicated that they have been in operation for a period of over 10 years.

\subsection{Business Advisory Centre's Operation in the Nkoranza South Municipality}

According to the key informants, the main roles of the Business Advisory Centre in the Nkoranza Municipality were to: providing access to business development services: building the entrepreneurial, technical and managerial capacity of clients to start and manage businesses; providing information and counselling to clients; promoting the establishment and strengthening of local business associations; leveraging resources from other stakeholders for medium and small enterprise (MSE) development activities; and facilitating access of clients to technology and finance.

The study examined the services provided by the BAC. The data showed that the Business Advisory Centre has a wide range of services for their clients. The key informants indicated that their main education and training areas were categorised into two thematic areas. These areas were technical training and managerial training services. In the area of technical training, they had training programmes for clients in the areas of: agro-processing comprising activities such as cassava processing (dough, starch, gari, and chips), palm oil processing, palm kernel oil extraction, groundnut processing, cashew processing and fruit processing; agro-industrial e.g. soap and detergent making, baking and confectionery; master craft training e.g. welding and fabrication, carpentry and joinery, masonry, leather work, textile weaving and dying, auto-mechanic, pottery, metal works, repairing agro-processing equipment, etc. farm-based business made up of entrepreneurs into bee keeping, mushroom farming, snail farming and grass cutter rearing; and other community-based training such as tailors, seamstress, hairdressers and batik tie and dye.

Apart from the above-mentioned technical training programmes organised for their clients, the BAC also regularly had managerial training programmes for their clients in the areas of management. Areas they organised such managerial education and training included: financial training (record keeping, savings habit), gender business training, customer service training, business plan preparation, leadership training, business promotion Entrepreneurs, according to the officials were often taken out of the municipality to Sunyani, Kumasi, Accra and even outside Ghana for study tour. Selected Beekeepers, for instance were sent to Denmark to enhance their knowledge in their trade last year. Again, two cashew farmers as at the time of the study were yet to return from a training tour in Kenya.

The key informants revealed that education and training services provided by the BAC, were basically aimed at equipping customers with the skills and knowledge they might need in going about their businesses and other activities. The education and training programmes were expected to result in changes in the attitudes of entrepreneurs, which would consequently have a positive effect on their operations and the communities in which they operated. Again, it is through training that entrepreneurs become aware of current practices and technological know-how [43].

Effort was made to find out from the clients (respondents) of the BAC if indeed they had received such 
education, training and other support services from the Centre. All the respondents answered in the affirmative confirming that indeed they have received education, training and other support services from the BAC. They indicated that the education and training programmes they received were in the areas of investment management, entrepreneurship, record keeping, business management, customer care, financial management, and business counseling which were all directed at improving upon their businesses and enhancing their livelihoods. All the respondents agreed that they had benefited from such education and training programmes by the BAC. Respondents were asked to indicate the number of times they had been part of such programmes. The majority $(85.9 \%)$ of the respondents indicated that they had received between 3-5 times of education and training from the BAC.

The key informants, specifically the Municipal Advisor of the BAC indicated that even though they had individuals as their clients, the majority $(80 \%)$ of them are mostly in groups. Examples of such groups in the Nkoranza Municipality included: Nkoranza Bee Keepers Association, Progressive Cashew Farmers Association, Grace Fabea Agro-processing Association, Ghana Federation of the Physically Challenged-Nkoranza, National Tailors and Dress Makers Association-Nkoranaza, Consecutive Hairdressers Association, Nkoranza Akunafo Kuo and Nkoranza Carpenters Association.

Attempt was made to ascertain the number of entrepreneurs that the centre had been able to train over the last five (5) years. The official document indicated that 1183 individuals had been trained and were still under their supervision [49]. The number of entrepreneurs trained over the period (2013- September, 2017) is presented in Figure 3. As can be seen in the figure, 81 entrepreneurs in the municipality were trained in 2013. The number increased to 121 in, 2014. In 2015 and 2016, 1887 and 309 entrepreneurs were trained respectively. In 2017, 484 entrepreneurs were trained [49].

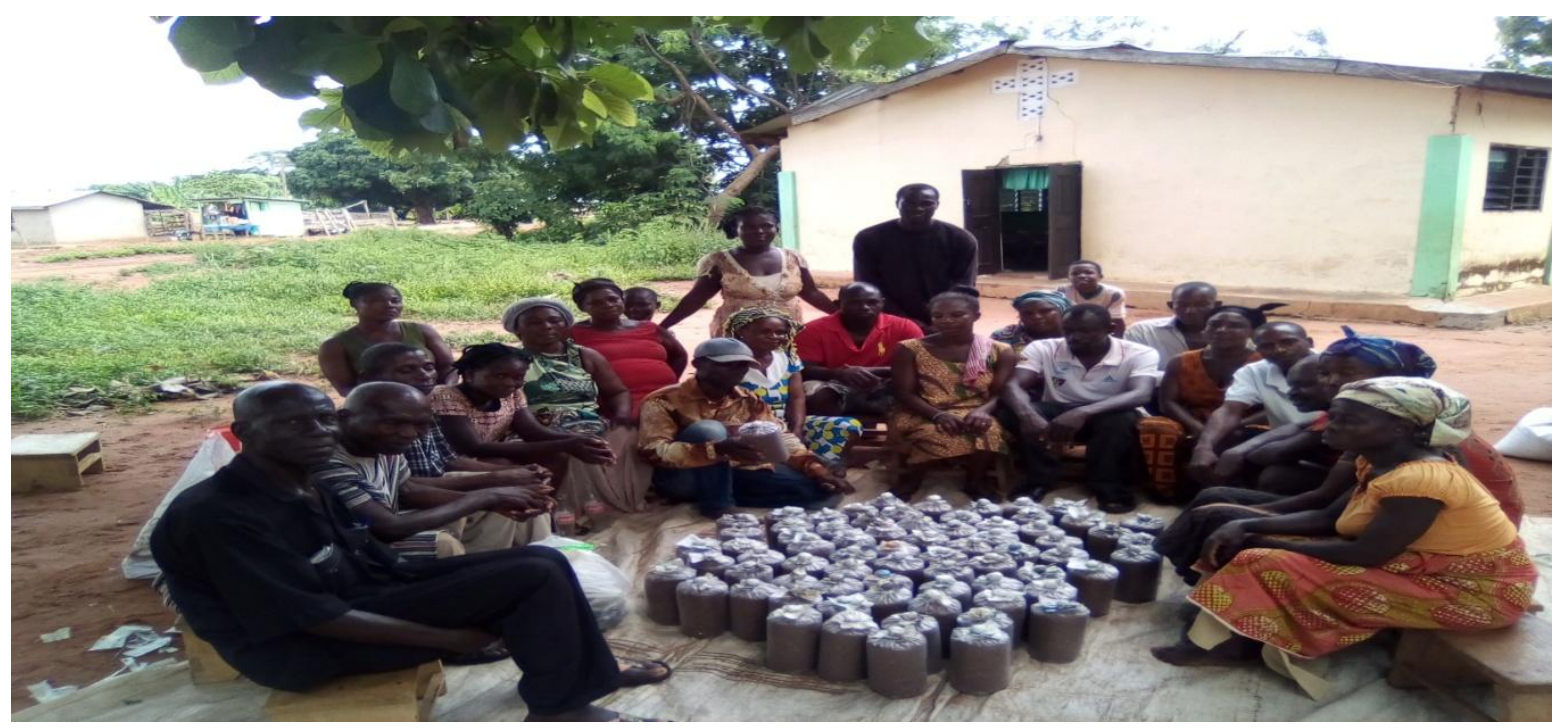

Plate 1. A cross-section of participants at Mushroom production training by the BAC

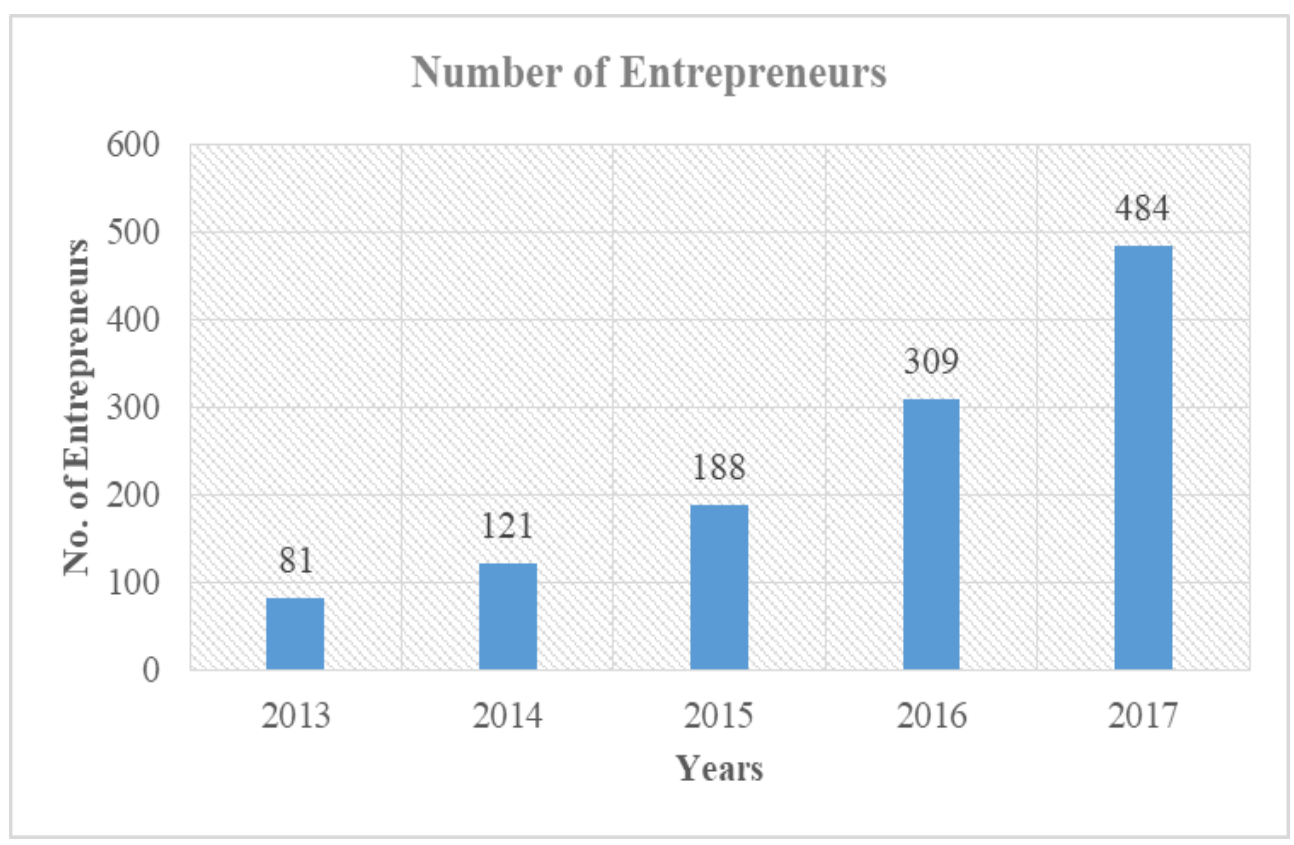

Figure 3. Trend in the Entrepreneurial education and training in the NSM by BAC (Between 2013- 2017) (Source: BAC Official Records (2017)) 
The BAC had also helped in the establishment of over 150 new businesses in 2017 and supported the revival of about 249 defunct businesses. It was also found that the $\mathrm{BAC}$, on the average, organised 25 training programmes annually. Apart from the training programmes often organised for their clients, they also helped their clients in acquiring loans and other logistics from financial institutions. Specifically, the Kwabre Rural Bank, Fiagya Rural Bank and the First Allied Bank were the main financial institutions that provided financial support to the clients of the BAC to establish and expand their businesses.

The study further examined the relevance of the training received. The respondents were asked to indicate whether the education and training they received from the BAC were relevant to their businesses and also indicate the extent to which they were satisfied with the education and training programmes organised by the Centre. All the respondents indicated that indeed the education and training they received were relevant to their various businesses and in terms of their satisfaction, the result is presented in Table 2 .

Table 2. Entrepreneurs' rating of the Education and Training programmes of BAC

\begin{tabular}{lll}
\hline Rating & Frequency & Percent \\
\hline Very satisfied & 107 & 38.5 \\
Satisfied & 163 & 58.6 \\
Indecisive & 2 & 0.7 \\
Dissatisfied & 5 & 1.8 \\
Very dissatisfied & 1 & 0.4 \\
\hline Total & 278 & 100.0 \\
\hline
\end{tabular}

Source: Field work, 2017.

As can be seen in Table 2, the majority (58.6\%) of the respondents were satisfied with the education and training programmes with $38.5 \%$ indicating that they were very satisfied with the education and training programmes offered them. However, 0.4 of the respondents indicated they were very dissatisfied. Those who were dissatisfied with the education and training programme indicated that the training period was short in their view.

\subsection{Effects of Education and Training on the Businesses and Poverty Reduction among Entrepreneurs}

The study consequently sought to find out whether the education and training programmes organised for the entrepreneurs had affected their businesses and their standards of living. It is discernible from Table 3 that, increased output or productivity was the important effect of education and training as observed by the respondents on their businesses. This was followed by increase in their levels of sales. Other effects of education and training on business development as revealed by the study included increase their customer base, increase in the number of their employees and apprentices and increase in their technological know-how. This findings corroborates of the findings of Abrisham and Khadijeh [8] that giving entrepreneurs education and training goes a long way to increase their productivity, number of employees and apprentices, and also helps them to adopt better business management practices.

Table 3. Effect of entrepreneurial education and training on business development

\begin{tabular}{llc}
\hline Responses & Frequency & Percent \\
\hline Increased production/output & 209 & 36.8 \\
Increased sales & 141 & 24.8 \\
Increased customers & 116 & 20.4 \\
Increased apprentices/workers & 60 & 10.6 \\
Increased technological know-how & 42 & 7.4 \\
\hline Total & $568^{*}$ & 100.0 \\
\hline
\end{tabular}

* Multiple responses exist

Source: Fieldwork, 2017.

The education and training programmes of the Business Advisory Centre was looked at in terms of how it had affected the livelihoods of their clients. The study further investigated how these services (education and training) rendered by BAC had reduced poverty levels among the respondents in terms of their outputs, incomes and savings level after the educational and training programmes by the BAC (Figure 2). A five-point Likert scale item format was used to assess the poverty indicators of customers before and after receiving education and training from the BAC. The Wilcoxon Signed-rank test was consequently conducted to find out how education and training programmes organised by the BAC has affected poverty the levels of the respondents.

Table 4. Effect of education and training on output/income/saving levels of entrepreneurs

\begin{tabular}{ccccc}
\hline Indicator & Mean before & Mean after & Z-value & P-value(sig) \\
\hline Output levels & 2.225 & 2.642 & 2.531 & $0.003^{*}$ \\
Income levels & 2.613 & 2.851 & 2.901 & $0.002^{*}$ \\
Savings level & 3.221 & 3.735 & 2.632 & $0.015^{*}$ \\
\hline
\end{tabular}

*Indicators significant at 5\% significance level Source: Fieldwork, 2017.

It is evident from the test in Table 4 that, the output level, income level and savings level of the respondents showed a statistically significant difference after they had undergone the education and training programmes by the BAC in the Nkoranza South Municipality. In other words, changes in respondents' output level, income level, savings level were statistically significant after they had received education and training from the BAC. This finding is consistent with [44], [33] and the conceptual framework (Figure 2) which identifies education and training as a way of breaking the poverty trap among small scale entrepreneurs. With the increases in their output, income and saving levels, respondents are in a better to provide medical care, good shelter, good education, nutritious food and clothing for their families. Furthermore, they are able to acquire assets and other properties. 


\subsection{Challenges facing educated and trained Small Scale entrepreneurs in the Nkoranza South Municipality}

In spite of the benefits that the respondents indicated they had derived from the education and training programmes of the BAC, they raised some challenges they are saddled with. The key challenge they faced according to the study had to do with start-up capital. They indicated that they were not able to provide the collateral securities that are demanded by the financial institutions. This was followed by low demand or patronage of their products. This according to the respondents stifles the growth and survival of their businesses. The other challenges revealed by the study include high tax and the lack of power/electricity.

Table 5. Challenges facing educated and trained small-scale entrepreneurs

\begin{tabular}{lll}
\hline Responses & Frequency & Percent \\
\hline Lack of start-up capital & 257 & 43.2 \\
Low demand/patronage of products & 201 & 33.8 \\
High tax & 88 & 14.8 \\
Lack of power/electricity & 49 & 8.2 \\
\hline Total & $595^{*}$ & 100.0 \\
\hline
\end{tabular}

* Multiple responses exist

Source: Fieldwork, 2017

\subsection{Challenges facing the $\mathrm{BAC}$ in Their Operations in the Nkoranza South Municipality}

In spite of the positive effect of the education and training programmes by the Business Advisory Centre in the Nkoranza South Municipality, there are myriad of challenges faced by the Centre in carrying out its mandate in the municipality. The key informants indicated that they were faced with financial challenge as they highly relied solely on the funds they received from the Rural Enterprise Programme (REP) and sometimes some funds from the National Board for Small-scale Industries (NBSSI). According to the key informants, the Municipal Assembly does not honor its commitment to the BAC. Apart from this, they were also challenged when it comes to vehicles to visit their clients. The informants indicated that their outfit oversees about 139 communities in the municipality and also communities in the Nkoranza North District. They have only one motor bicycle at their disposal for all their activities. This does not help them to do effective monitoring and evaluation within their catchment area.

\section{Conclusions and Policy Recommendations}

The focal point of this paper was to examine how education and training services provided by the Business Advisory Centre (BAC) has contributed to poverty reduction among small-scale entrepreneurs in the Nkoranza South Municipality. Firstly, the results of the study have shown that the BAC has a wide range of education and training programmes for its clients. These programmes were put in to two thematic areas namely technical and managerial education and training programmes. Secondly, it was revealed that the education and training programmes provided by BAC in the Nkoranza South Municipality have affected positively the living standards (reduced poverty) of entrepreneurs within the catchment area. This was manifested in the positive changes that were shown in their levels of output, income, savings, and consequently, their ability to provide medical care, good education, shelter, nutritious food for their families and also their ability to acquire property and other assets.

It is recommended that the centre opens its doors widely and extend their facilities to the youth and other entrepreneurs who are not registered with them in the municipality. Again, the Rural Enterprise Programme (REP), the NBSSI and the Municipal Assembly should endeavour to make funds readily available to the centre for their programmes in the municipality. Furthermore, the Centre should be provided with a vehicle and other logistics for their smooth operation in the municipality as the only vehicle they had was broken down beyond repairs.

\section{Acknowledgements}

The authors wish to thank the officials of the Business Advisory Centre (Nkoranza) especially Mr. Isaac Asirifi Agyemang and also Mr. Opoku Benjamin of the Social Welfare and Community Development, for their immense contributions. Again, Messrs. Derick Adu Taylor (Freshmacs Ghana Limited) and Samuel Owusu (Methodist Senior Highs School- Saltpond) deserve special thanks for their assistance towards the study.

\section{References}

[1] African Union, Strategy for the implementation of the plan of action for the accelerated industrial development of Africa, African Union Addis Ababa, Ethiopia, 2008

[2] United Nations, Labour migration, remittances, and human development in Central Asia. United Nations, New York, 2015.

[3] World Bank, Poverty and shared prosperity 2016: Taking on inequality. World Bank, Washington, DC, 2016.

[4] European Union, Accountability report 2012: Review of progress of the EU and its member states financing for development, European Union, Brussels, 2012

[5] C. Liedholm, and E. Chuta, (2010). The economics of rural and urban small-scale industries in Sierra Leone. African Rural Economy Paper, No.14, 2010, 150.

[6] J. Page, and M. Soderbom, (2015). Is small beautiful? Small enterprise, aid and employment in Africa. African Development Review, 27(S1), 2015, 44-55.

[7] H. M. Priyanath, Managerial deficiencies in the small and medium enterprises in Sri Lanka: An empirical evidence of SMEs in Rathnapura District. Sabaragamuwa University Journal, 6 (1), 2006, 93-105

[8] A. Abrisham, and A. Khadijeh, The barriers of educational development in rural areas of Iran. Indian Journal of Science and Technology, 5(2), 2012.

[9] F. Burchi, and P. De Muro, Education for rural people: A neglected key to food Security, Working Paper No. 78, Food and Agriculture Organisation Rome, 2007.

[10] E. Royce,. Poverty and power: A perspective on American inequality. Rowman and Littlefield Publishers Lanham, Maryland: 2009 
[11] W. T. Schultz, Transforming traditional agriculture, Lyall Book Depot Ludhiaha, 1964

[12] M. Cowling, Are entrepreneurs different across countries? Applied Economic Letter, 7(12), 2000, 785-789.

[13] G. Psacharopoulos, and M. Woodhall, Education for development: An analysis of investment choice, Oxford University Press, New York, 1997.

[14] S. S. Zidan, The role of HRD in economic development. Human Resources Development Quarterly, 12(4), 2001, 437.

[15] Ghana Statistical Service, Population census of Ghana: Demographic and economic characteristics, Ghana Statistical Service, Accra: 1984

[16] T. A. Adisa, I. Abdulraheem, and C. Mordi, The characteristics and challenges of small businesses in Africa: An exploratory study of Nigerian small business owners. Economic Insights-Trends and Challenge, 3(66), 2014, 1-14

[17] S. Mensah, A review of SME financing schemes in Ghana. Paper presented at the UNIDO Regional Workshop of Financing Small and Medium Scale Enterprises, Accra, Ghana, 2004, $15^{\text {th }}-16^{\text {th }}$ March.

[18] J. Abor, and P. Quartey, Issues of in SME development in Ghana and South Africa. International Research Journal of Finance and Economics, 39, 2010, 218-228.

[19] K. I. Dandago, A. Y. Usman, Assessment of Government industrialisation policies on promoting the growth of small-scale industries in Nigeria, Paper presented at the 2011 Ben-Africa conference, Zanzibar, Tanzania, 2011.

[20] European Commission, Guide for training in SMEs. European Commission, Brussels, 2009

[21] P. J. A. Robson, H. H. Haugh, and B. A. Obeng, Entrepreneurship and innovation in Ghana: Enterprising in Africa. Small Business Economics, 15(3), 2009, 193-208.

[22] P. Kearns, Are two worlds colliding? The provision of training and learning services for small business, NCVER, Adelaide, 2002.

[23] FAO \& UNESCO, Education for rural development: Towards new policy responses, Rome \& Paris: FAO \& UNESCO, 2003.

[24] G. S. Becker., Human capital: A theoretical and empirical analysis, with special reference to education. Chicago, IL: University of Chicago Press, 1993.

[25] C. W. Njoroge, and J. M. Gathungu, The effect of entrepreneurial education and training on development of small and medium size enterprises in Githunguri District- Kenya. International Journal of Education and Research, 1(9), 2013, 1-22.

[26] Y. Cho, and M. Honorati, Entrepreneurship programs in developing countries: A meta regression analysis. Labour Economics, 28, 2014, 110-130.

[27] F. Enu-Kwesi, F. Koomson, and R. Baah-Mintah, The contribution of Kakum Rural Bank to poverty reduction in the Komenda-Edina-Eguafo-Abrem Municipality in the Central Region, Ghana. Economic Annals, 58(197), 2013,121-140.

[28] R. I. Rahman, and K. M. N. Islam, Employment poverty linkages, Bangladesh. ILO, Recovery and Reconstruction Department Geneva, 2003.

[29] A. Robb, A. Valerio, and B. Parton (Eds.), Entrepreneurship education and training: Insights from Ghana, Kenya and Mozambique. Washington, D.C.: World Bank, 2014.

[30] S. Dawe, and N. Nguyen, Education and training that meets the needs of small business: A systematic review of research. National Centre for Vocational Education Research, Adelaide, 2007.

[31] G. K. Frempong, Change Agents in Small-Scale Industries Development in Ghana: A Review. National Development Planning Bulletin, 1(1), 1997, 33-41.
[32] E. E. Yamoah, S. Arthur, and A. Issaka, Institutional Framework for Promoting Small and Medium Scale Enterprises in Ghana: Perspective of Entrepreneurs. Australian Journal of Business and Management Research, 3(10), 2014, 28-45.

[33] Polak, P. (2009). Out of poverty: What works when traditional approaches fail, Berret-Kochler Publishers, Inc., San Francisco, 2009.

[34] W. M. Ladzani, and J. J. van Vuure, Entrepreneurship training for emerging SMEs in South Africa. Journal of Small Business Management, 40(2), 2002, 151-161.

[35] A. Dos Vos, and I. Willemse, Leveraging training skills development in SMEs: An analysis of East-Flanders, Belgium, OECD, Paris, 2011.

[36] D. Kayanula and P. Quartey, The policy environment for promoting small and medium sized enterprise in Ghana and Malawi. Finance and Development Research Programme Working Paper. Series No.15, 2000

[37] E. E. Smith, and S. Perks, Training interventions needed for black micro-entrepreneurial skills in the informal sector A qualitative perspective. South African Journal of Human Resource Management, 4(1), 2006, 17-26.

[38] J. H. Owusu-Acheampong, Rural credit and rural development in Ghana. In C. K. Brown (Ed.), Rural development in Ghana. Accra: Ghana Universities Press, 1986.

[39] I. K. Magableh, and R. Kharabsheh, Determinants and impact of training: The case of SMEs in Jordan. International Journal of Economics and Finance, 3(5), 2011

[40] A. Gibson, Business development services core principles and future challenges. Small Enterprise Development, 8(3), 1997, 4-14

[41] L. Goldmark, The financial viability of business development services. Small Enterprise Development, 10(2), 1999, 4-16.

[42] P. O. Idogho, and A. E. Ainabor, Entrepreneurship Education and Small-Scale Business Management Skill Development among Students of Auchi Polytechnic Auchi, Edo State, Nigeria. International Journal of Business and Management, 6(3), 2011, 84-288.

[43] S. Nyoni, Small, micro \& medium enterprises (SMMEs), policy \& strategy framework, Printflow, Harare, 2002.

[44] T. Beck, A. Demirguc, and R. Levin, Financial and legal constraints to firm growth: Does size matter? World Bank, Washington, D.C., 2005.

[45] R. V. Krejcie and D. W. Morgan. Determinning sample size for research activities. Educational and Psychological Meaurement, 30, 607-610, 1970.

[46] N. J. Amu, The role of women in Ghana's economy, Friedrich Ebert Stiftung, Accra, 2005.

[47] I. Sulemana, Factors influencing the performance of small-scale entrepreneurs in the garment industry of the Tamale Metropolis in Ghana. Unpublished M.Phil. thesis, University of Ghana, Accra, 014.

[48] R. C. Rose, N. Kumar, and L. L. Yen, The dynamics of entrepreneur's success factors in influencing venture growth. Journal of Asian Entrepreneurship and Sustainability, 2(3), 2006.

[49] Business Advisory Centre (BAC), Official report 2017. BAC, Nkoranza, 2017.

[50] M. Cowling, Impact of entrepreneurship training and small business experience on future entrepreneurial activity in the UK. IES Working Paper (WP21), 2009. 